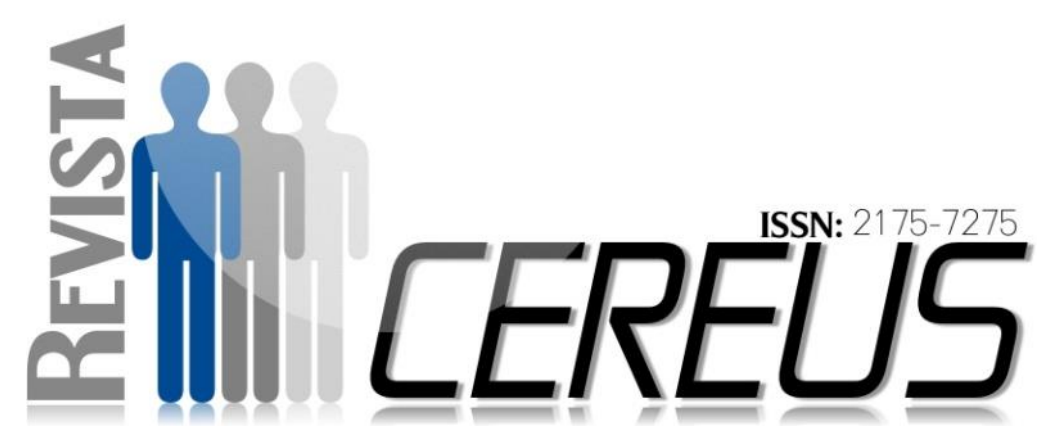

DOI:10.18605/2175-7275/cereus.v9n1p.76-87

\title{
INCENTIVOS FISCAIS NO ESTADO DE TOCANTINS: 1988-
}

\section{7}

ALVES, Patrícia Pinheiro ${ }^{1}$ KAMIMURA, Quesia Postigo ${ }^{2}$

\section{RESUMO}

Estudar as políticas públicas e sua evolução, é uma forma de analisar sua implementação efetiva, uma vez que a sua formulação está calcada em justiça social. O objetivo desta pesquisa foi apresentar a evolução histórica dos programas de incentivos fiscais utilizados como estímulo para indústria, implementados no Tocantins, desde sua criação até o período de 2017. Para análise da política pública fiscal foi necessário estudo do papel do Estado e do mercado no processo de desenvolvimento econômico com inclusão social. Numa abordagem qualitativa, a pesquisa teve como base o estudo exploratório e explicativo, quanto aos procedimentos foi documental e histórica. Para o desenvolvimento da pesquisa, utilizou-se do rol das leis tributárias criadas no Tocantins

\footnotetext{
${ }^{1}$ Mestre em Desenvolvimento Regional pela Universidade de Taubaté- UNITAU. E mail para correspondência: patty3110@hotmail.com

2 Professora do programa de mestrado da Universidade de Taubaté- UNITAU; Doutora em Saúde Pública.
}

v. 9, n. 1, jan/abr. 2017 UnirG, Gurupi, TO, Brasil 
destinadas a promoção do desenvolvimento regional sustentável. A história dos incentivos fiscais no Tocantins, demonstra ausência de procedimentos que reavaliem de forma periódica os programas em execução e a relação entre a atuação empresarial e o desenvolvimento sócio-econômico da região.

Palavras-chave: Políticas Públicas. Política Fiscal. Incentivos Fiscais.

\section{TAX INCENTIVES IN TOCANTINS: 1988-2017}

\section{ABSTRACT}

Studying public policies and their evolution is a way to analyze their effective implementation, since its formulation is based on social justice. The objective of this research was to present the historical evolution of the tax incentive programs used as stimulus for industry, implemented in Tocantins, from its creation until the period of 2017 . For the analysis of public fiscal policy, it was necessary to study the role of the State and the market in process of economic development with social inclusion. In a qualitative approach, the research was based on the exploratory and explanatory study, regarding the procedures was documentary and historical. For the development of the research, we used the list of tax laws created in Tocantins to promote sustainable regional development. The history of tax incentives in Tocantins demonstrates the absence of procedures that periodically reassess the programs in execution and the relationship between the business performance and the socio-economic development of the region.

Key words: Public Policies. Fiscal Policy. Tax breaks. 


\section{INTRODUÇÃO}

Após a crise de 1929, onde abalou a estrutura da economia mundial, nasceu o interesse pelo bemestar social, com objetivo de construir políticas voltadas para melhoria na qualidade de vida da sociedade. O papel do Estado é de fundamental importância para o desenvolvimento de um país, alinhando as funções e as estruturas econômicas e política.

Estudar as políticas fiscais adotadas por uma região é uma forma de analisar as condições necessárias

\section{POLÍTICAS PÚBLICAS}

As políticas públicas são uma das resultantes da atividade política, compreendem o conjunto de decisões e ações relativas à alocação imperativa de valores envolvendo bens públicos (RUA, 2009, p.19).

Existem várias definições para políticas públicas, dentre elas Souza (2006, p.24, apud MEAD, 1995) define como um campo dentro do estudo da política que analisa o governo à luz de grandes questões públicas. A política pública é um conjunto de ações governamentais que irão gerar efeitos específicos (SOUZA, 2006 apud LYNN, 1980). Conceitua-se ainda Rev. Cereus, v. 9, n. 1, p.76-8 para que os cidadãos e suas empresas tenham condições de suportar a carga tributária sem comprometer a própria existência ou a lucratividade necessária.

Este artigo foi parte de uma pesquisa de mestrado na área de gestão e desenvolvimento regional, e teve como objetivo apresentar a evolução histórica dos programas de incentivos fiscais implementados no Tocantins, desde 1988 até o ano de 2017.

como sendo a soma das atividades dos governos, que agem diretamente ou através de delegação, e que influenciam a vida dos cidadãos (SOUZA, 2006 apud PETERS, 1986). Para Mendes et al $(2010$, p. 4) "cabe refletir sobre como são desenvolvidas as políticas públicas, principalmente as locais (municipais), e que relação estabelecem com a condição de vida dos cidadãos".

$\mathrm{Na}$ política pública o governo escolhe fazer ou não fazer (SOUZA, 2006 apud DYE, 1984). Segundo Souza (2006, p.24) "a definição mais conhecida continua sendo a de /2017, UnirG, Gurupi, TO, Brasil. 
Laswell, ou seja, decisões e análises sobre política pública implicam responder às seguintes questões: quem ganha o quê, por quê e que diferença faz".

Para Hofling (2001, p.31) política pública pode ser entendida então como "o Estado implantando um projeto de governo, através de

\subsection{POLÍTICA FISCAL}

O Estado, como a sociedade política, tem um fim geral que é a promoção do bem comum, compreendido como conjunto de todas as condições de vida social que consintam e favoreçam 0 desenvolvimento integral da personalidade humana (FEITOSA, KAMIMURA, 2011 apud TRAMONTIN, 2008). "Uma análise histórica permite que se diga que o Estado, ao longo do tempo, tem assumido diferentes formas de atuação, no que diz respeito a sua interação com a sociedade (MENDES et al, 2010, p.16)".

A política fiscal partiu do entendimento que o uso consciente dos meios fiscais do governo (tributação, gastos e dívida pública), com o objetivo de neutralizar as tendências cíclicas da economia, traduzidas por inflação e recessão, programas, de ações voltadas para setores específicos da sociedade".

O processo de implementação das políticas públicas, seja de cunho social ou econômico, é de interesse do poder público em atuar junto ao problema eleito como prioridade de ação (SANTOS; OLALDE, 2011, p.3).

inspirando tempos depois, um tipo de política fiscal orientada para o fomento do crescimento econômico (PEREIRA, 2010).

Para Pereira (2010) a política fiscal orienta-se em duas direções: política tributária (captação de recursos para atendimento das funções da administração pública) e política orçamentária (refere-se aos gastos, relacionados com a forma de aplicação dos recursos).

Um dos objetivos fundamentais da República Federativa do Brasil, previsto no art. 3 , inciso II, da CF, é o princípio do desenvolvimento nacional, no sentido de que o Estado deve perseguir 0 desenvolvimento em atuação conjunta com a iniciativa privada, devendo a ordem econômica estar voltada para a construção de uma sociedade mais justa e solidária 
(FEITOSA, KAMIMURA, 2011 apud TRAMONTIN, 2002, p.57).

Neste sentido, a política fiscal, através dos incentivos fiscais oferecidos, representam técnicas para alcançar determinados objetivos, sendo o principal a busca pelo desenvolvimento econômico (FEITOSA, KAMIMURA, 2011 apud TRAMONTIN, 2002).

\subsection{INCENTIVOS FISCAIS}

A palavra incentivo tem significado de estímulo, benefício, vantagens, estímulos permitidos pelo governo, na área fiscal, para que recursos sejam canalizados para segmentos específicos (econômico, cultural, social) (ESTIGARA; PEREIRA; LEWIS, 2009).

A concessão deverá promover equilíbrio sócio-econômicos entre diferentes regiões, que segundo Hack (2010) só poderá ser admitida se observado alguns requisitos: Equilíbrio do desenvolvimento nas regiões do Brasil: o incentivo visará o equilíbrio do desenvolvimento das regiões, não permitindo situações favoráveis para uma delas em prejuízo das demais. Deverá incrementar a situação econômica da região beneficiada, e a melhora nas condições de vida desta população.

No art. 174 da Constituição Federal, Cretella Júnior (1993) comenta que o incentivo é a segunda das funções exercidas pelo Estado, sendo este um agente normativo e regulador da atividade econômica, os incentivos podem ser de natureza não fiscal quando ocorrem doações de áreas para exploração de atividades econômicas, como podem ser de natureza fiscal, como exemplos as isenções de tributos.

O incentivo fiscal é a medida
imposta pelo Poder Executivo,
com base constitucional, que
exclui total ou parcialmente o
crédito tributário de que é
detentor o poder central em prol
do desenvolvimento de região ou
de setor de atividade do
contribuinte (CRETELLA, 1993,
p.3.585).

Sendo assim, com a prática de incentivos fiscais, o Estado deixa de recolher impostos, e em troca esperase a expansão econômica de certa região ou atividade econômica.

São incentivos fiscais do Tocantins os programas: Proindústria, Prosperar, E-commerce de incentivo ao comércio varejista de mercadorias, exclusivamente via internet, Comércio 
atacadista de medicamentos, Complexo agroindustrial, Comércio atacadista, Produção de frutas e de pescado, Micro empresas e empresas de pequeno porte, Produção de carne (TOCANTINS, 2017).

\section{METODOLOGIA}

A pesquisa teve como base 0 estudo exploratório e explicativo, e quanto a abordagem foi aplicado a pesquisa qualitativa.

Quanto aos procedimentos ela foi documental e histórica. Os documentos utilizados como base de

\section{RESULTADOS E DISCUSSÃO}

Estado do Tocantins foi criado em 1988, e seu primeiro Código Tributário, a Lei no 109/89 não apresentou em seu texto nenhum incentivo fiscal para promoção do desenvolvimento e redução das desigualdades regionais, mesmo sendo determinado na Constituição Federal/88, em seu art. 174 "que o Estado exercerá na forma da lei, as funções de fiscalização,
Dentre as políticas públicas, 0 Prosperar e o Proindústria, são instrumentos do Estado, no intuito da geração de emprego e distribuição de rendas, promovendo desenvolvimento regional sustentável do Estado do Tocantins.

análise foram as leis tributárias criadas no Tocantins, destinadas a promoção do desenvolvimento regional sustentável, voltadas para o estímulo a indústria, desde 1988 até o ano de 2017. incentivos e planejamento, sendo este determinante para o setor público".

No quadro abaixo é apresentado a evolução histórica dos programas de incentivos fiscais voltados para o estímulo da indústria, o Prosperar e o Proindústria, implementados no Tocantins, desde sua criação até o período de 2017. 


\begin{tabular}{|c|c|c|c|}
\hline ANO & LEI & \multicolumn{2}{|c|}{ DESCRIÇÃO } \\
\hline 1989 & 59 & $\begin{array}{l}\text { Cria o Programa de Incentivo ao } \\
\text { Desenvolvimento Econômico }\end{array}$ & $\begin{array}{l}\text { Estimula o fluxo de investimento } \\
\text { para o Estado. }\end{array}$ \\
\hline 1992 & 494 & $\begin{array}{l}\text { Cria o fundo para prover recursos } \\
\text { ao programa PROGREDIR }\end{array}$ & $\begin{array}{l}\text { Constitui recursos das dotações } \\
\text { orçamentárias para implantação de } \\
\text { distritos, áreas e r setores } \\
\text { industriais. }\end{array}$ \\
\hline 1995 & 761 & $\begin{array}{l}\text { Altera o nome do programa para } \\
\text { PROSPERAR }\end{array}$ & $\begin{array}{l}\text { Estimula o crescimento sistemático } \\
\text { e ordenado da economia do } \\
\text { Estado, por meio de concessão de } \\
\text { estímulos financeiros a fim de } \\
\text { elevar o nível de qualidade de vida } \\
\text { da população. }\end{array}$ \\
\hline 2000 & 1184 & & $\begin{array}{l}\text { Concede incentivos aos complexos } \\
\text { agroindustriais. }\end{array}$ \\
\hline 2002 & 1349 & $\begin{array}{l}\text { Cria incentivo para instalação de } \\
\text { indústrias automotivas e de } \\
\text { fertilizantes }\end{array}$ & \\
\hline 2002 & 1355 & $\begin{array}{l}\text { Define o PROSPERAR como } \\
\text { instrumento de política de } \\
\text { desenvolvimento do Estado }\end{array}$ & $\begin{array}{l}\text { Financia o imposto devido, de } \\
\text { forma a permitir a auto- } \\
\text { sustentabilidade, incrementando a } \\
\text { geração de emprego e renda, e a } \\
\text { distribuição de riquezas do Estado. }\end{array}$ \\
\hline 2003 & 1385 & $\begin{array}{lcr}\text { Institui o } & \text { Programa } & \text { de } \\
\text { Industrialização } & \text { Direcionada- } \\
\text { PROINDUSTRIA } & \end{array}$ & $\begin{array}{l}\text { Promove a interiorização da } \\
\text { atividade industrial, gerar emprego } \\
\text { e renda, estimular a utilização e a } \\
\text { transformação da matéria-prima } \\
\text { local, uso sustentável de recursos } \\
\text { naturais, gradativa desoneração da } \\
\text { produção. }\end{array}$ \\
\hline 2003 & 1392 & Altera o $\S 1$ da Lei 1.385/03 & $\begin{array}{l}\text { Apresenta como finalidade } 0 \\
\text { estímulo a instalação de indústrias } \\
\text { no Estado. }\end{array}$ \\
\hline 2006 & 1.665 & Altera a Lei $1.385 / 03$ & $\begin{array}{l}\text { Acrescenta a alínea "c" ao inciso II } \\
\text { do artigo } 4 \text { } \text {, onde o benefício do } \\
\text { crédito presumido passa a ser } \\
\text { também nas saídas praticadas por } \\
\text { estabelecimento abatedor de gado } \\
\text { bovino. }\end{array}$ \\
\hline 2006 & 1.695 & 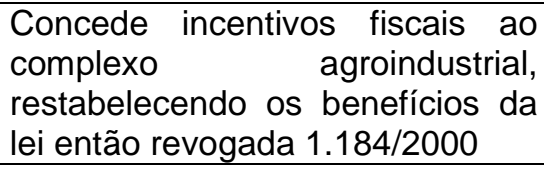 & \\
\hline 2007 & 1.762 & Altera a Lei $1.385 / 03$ & $\begin{array}{l}\text { Concede isenção do ICMS, nas } \\
\text { importações de produtos utilizados } \\
\text { nos processos de industrialização. }\end{array}$ \\
\hline $\begin{array}{l}2008- \\
2017\end{array}$ & & & tema proposto. \\
\hline
\end{tabular}

Fonte: Elaborado pelos autores (SEFAZ, 2017)

Foram criadas e/ou alteradas várias leis no Estado, no intuito de incrementar a economia local, estimulando 0 desenvolvimento econômico por meio da melhoria na qualidade de vida e geração de renda. Neste contexto os programas PROSPERAR e PROINDÚSTRIA 
tiveram um destaque maior entre os demais.

O Programa de Incentivo ao Desenvolvimento Econômico do Estado do Tocantins - PROSPERAR, é definido como instrumento de política de desenvolvimento do Estado destinado ao financiamento do imposto devido pela empresa beneficiária, de forma a permitir-lhe a autosustentabilidade, incrementando a geração de emprego e renda e a distribuição de riquezas no Estado.

Com a Lei no 1.385/2003, é instituído o Programa de Industrialização Direcionada PROINDÚSTRIA, com finalidade de promover a interiorização da atividade industrial; a geração de emprego e renda; o estímulo à utilização e à transformação de matéria-prima local; o uso sustentado dos recursos naturais; e a gradativa desoneração da produção (TOCANTINS, 2017).

Sua concessão era estabelecida pela aprovação do projeto de instalação ou expansão, não podendo

\section{CONCLUSÃO}

A política de incentivos fiscais tem suas justificativas apresentadas pelos gestores para as concessões de incentivos para empresas privadas usufruir dos incentivos os beneficiários que apresentasse

alguma irregularidade junto ao fisco estadual. Este incentivo compreendia: isenção de ICMS; crédito presumido; a inexigibilidade do ICMS na substituição tributária em operação que destine mercadoria a estabelecimento para utilização em processo de produção, industrialização ou manipulação; e autorização, durante a fase préoperacional (TOCANTINS, 2017).

Os benefícios desta Lei eram concedidos mediante aprovação de carta-consulta pela SecretariaExecutiva do Conselho Estadual de Desenvolvimento Econômico e sua fruição sujeito ao cumprimento das normas estabelecidas em regulamento, condicionando a manutenção do benefício, obrigação do beneficiário de pagar $0,3 \%$ de seu faturamento mensal, a título de contribuição de custeio, para o Fundo de Desenvolvimento Econômico (TOCANTINS, 2017). instalarem-se em suas unidades territoriais, apoiadas no desenvolvimento local, para geração de renda e empregos. 
No Tocantins, como no restante do país, apresenta grande quantidade de incentivos fiscais, com finalidade de estimular novas indústrias ou outras atividades econômicas, o que muitas vezes na prática, não representa nenhum crescimento

ou desenvolvimento local, ou mesmo uma política eficiente no que diz respeito ao combate às desigualdades socioeconômicas.

É necessário procedimentos que reavaliem de forma periódica os programas em execução criando possibilidades de remanejamento dos recursos disponíveis. Através de análise bem feita pode-se ter uma redução dos encargos financeiros ou da carga tributária, estimulando 0 processo de crescimento, oferecendo subsídios para o desenvolvimento sustentável. Uma proposta para fruição dos benefícios deste tipo de política, seria uma análise das empresas, de forma a demonstrar a relação entre a sua atuação desenvolvimento econômico e social da região, e através de mecanismos de avaliação instituído pelos gestores públicos, é que ocorreria tão concessão.

Caberia ao gestor público também, um estudo sobre o grau de especialidade de cada região, no intuito de averiguar a quantidade de beneficiários que poderiam vir a usufruir do incentivo, direcionando estes incentivos conforme a importância para a região.

Em síntese, o Estado do Tocantins, como vários estados da federação, tem grandes desafios a serem superados no campo dos incentivos fiscais, que é: melhorar a utilização dos instrumentos existentes, tornar as regras mais claras, e por fim, tornar os incentivos acessíveis a todos.

\section{REFERÊNCIA}

ANDRADE, Maria Margarida de. Como preparar trabalhos para cursos de pósgraduação: noções práticas. 5. ed. São Paulo: Atlas, 2002.

CRETELLA JUNIOR, José. Comentários a constituição brasileira de 1988. vol. VII. Rio de Janeiro: Forense, 1993. 
ESTIGARA, Adriana; PEREIRA, Reni; LEWIS, Sandra A. Lopes Barbon. Responsabilidade social e incentivos fiscais. São Paulo: Atlas, 2009.

FEITOSA, Patricia Pinheiro Alves; KAMIMURA, Quesia Postigo. INCENTIVOS FISCAIS NO ESTADO DE TOCANTINS: 1988-2010. Disponível em:< http://www.inicepg.univap.br/cd/INIC_2011/anais/arquivos/0543_0492_01.pdf >. Acesso em: 06/04/2017.

HACK, Érico. Incentivos fiscais ao desenvolvimento regional. Disponível em: <http://jus2.uol.com.br/DOUTRINA/texto.asp?id=10522>. Acesso em: 17/05/ 2010.

HOFLING, Eloisa de Mattos. Estado e políticas (públicas) sociais. Cadernos Cedes, ano XXI, n-55, Nov/2001. Disponível em: <http://www.scielo.br/pdf/ccedes/v21n55/5539.pdf>. Acesso em: 03/03/2011.

MENDES, Ana Maria C. Pereira et al. Políticas públicas, desenvolvimento e as transformações do Estado brasileiro. In: SILVA, Christian Luiz da \& SOUZA-LIMA, José Edmilson de (Org.). Políticas públicas e indicadores para o desenvolvimento sustentável. São Paulo: Saraiva, 2010. p.3-34.

PEREIRA, José Matias. Finanças públicas: a política orçamentária no Brasil. 5. ed. São Paulo: Atlas, 2010.

RICHARDSON, Roberto Jarry. Pesquisa Social: métodos e técnicas. 3 ed rev. e amp. São Paulo: 1999. Editora Atlas SA.

RUA, Maria das Graças. Análise das políticas públicas: conceitos básicos. Disponível em:http://empreende.org.br/pdf/Democracia\%20e\%20Participa\%C3\%A7\%C3\%A3o/ An\%C3\%A1lise\%20de\%20Pol\%C3\%ADticas\%20P\%C3\%BAblicas\%20\%20Conceitos\%20B\%C3\%A1sicos.pdf>. Acesso em: 03/03/2011.

SANTOS, Carlos Eduardo R.; OLALDE, Alícia Ruiz. Desenvolvimento regional e políticas públicas: a isenção fiscal como ferramenta de promoção do desenvolvimento regional no Sudoeste da Bahia. Disponível em: <http://aplicativos.fipe.org.br/enaber/pdf/153.pdf>. Acesso em: 03/03/2011.

SILVA, Marise Borba de; GRIGOLO, Tânia Maris. Metodologia para iniciação científica à prática da pesquisa e extensão II. Caderno Pedagógico. Florianópolis: UDESC, 2002.

SOUZA, Celina. Políticas Públicas: uma revisão da literatura. Sociologias. Porto Alegre, ano 8, no 16, jul/dez 2006, p. 20-45. Disponível em: <http://www.scielo.br/pdf/soc/n16/a03n16.pdf>. Acesso em: 03/03/2011.

TOCANTINS. Lei no 1.746, de 15 de dezembro de 2006. Cria o Conselho Estadual de Desenvolvimento Econômico e o Fundo Estadual de Desenvolvimento Econômico, e adota outras providências. Diário Oficial do 
Estado do Tocantins $\mathrm{n}^{\circ} \quad 2.309 . \quad$ Disponível em:<http://dtri.sefaz.to.gov.br/legislacao/ntributario/Leis/lei1.746-06.pdf>. Acesso em: 14/04/2017.

. Lei no 059, de 28 de junho de 1989. Cria o Programa de Incentivo ao Desenvolvimento Econômico do Tocantins - IDE-TOCANTINS e dá outras providências. Diário Oficial do Estado do Tocantins $\mathrm{n}^{\circ}$ 19. Disponível em: <http://www.al.to.gov.br/arq/AL_arquivo/6319_Lei059_89.pdf>. Acesso em: 14/04/2017.

Lei no 109, de 21 de dezembro de 1989. Institui o Código Tributário. Diário Oficial do Estado do Tocantins no 27. Disponível em:<http://dtri.sefaz.to.gov.br/>. Acesso em: 14/04/2017.

. Lei no 494, de 15 de dezembro de 1992. Cria o Fundo para prover de recursos o Programa de Incentivo ao Desenvolvimento Industrial do Estado do Tocantins. Diário Oficial do Estado do Tocantins no 191. Disponível em:<http://dtri.sefaz.to.gov.br/>. Acesso em: 14/04/2017.

. Lei no 761, de 08 de junho de 1995. Cria o Programa de Incentivo ao Desenvolvimento Econômico do Estado do Tocantins - PROSPERAR, dá nova denominação ao fundo que especifica e outras providências. Diário

Oficial do Estado do Tocantins no 441. Disponível em: <http://dtri.sefaz.to.gov.br/>. Acesso em: 14/04/2017.

. Lei $\mathrm{n}^{0}$ 1.349, de 13 de dezembro de 2002. Incentiva a instalação de indústrias automotivas no Estado do Tocantins, e adota outras providências. Diário Oficial do Estado do Tocantins n⒈342. Disponível em:<http://dtri.sefaz.to.gov.br/>. Acesso em: 14/04/2017.

. Lei $\mathrm{n}^{0}$ 1.355, de 19 de dezembro de 2002. Dispõe sobre o Programa PROSPERAR e o FUNDO PROSPERAR, e adota outras providências. Diário Oficial do Estado do Tocantins $n^{\circ}$ 1.345. Disponível em:<http://www2.sefaz.to.gov.br/Leis/lei1.355-02.htm>. Acesso em: 14/04/ 2017.

Lei no 1.385, de 9 de julho de 2003. Institui o Programa de Industrialização Direcionada - PROINDUSTRIA, e adota outras providências. Diário Oficial do Estado do Tocantins nำ 1.472. Disponível em:

<http://dtri.sefaz.to.gov.br/legislacao/ntributaria/Leis/lei1.385-03.htm>. Acesso em: 14/04/2017.

. Lei $\mathrm{n}^{\circ} 1.392$, de 22 de agosto de 2003. Altera a Lei 1.385, de 9 de julho de 2003, que institui o Programa de Industrialização Direcionada PROINDÚSTRIA. Diário Oficial do Estado do Tocantins nำ 1.509. Disponível em: <http://dtri.sefaz.to.gov.br/>. Acesso em: 14/04/2017.

. Lei $n^{\circ} 1.665$, de 22 de fevereiro de 2006. Altera as Leis 1.173, de 2 de agosto de 2000, que autoriza a redução da base de cálculo do ICMS, e 1.385, de 9 de julho de 2003, que instituiu o Programa de Industrialização Direcionada PROINDÚSTRIA, e adota outras providências. Diário Oficial do Estado do Rev. Cereus, v. 9, n. 1, p.76-87, jan-abr./2017, UnirG, Gurupi, TO, Brasil. 
Tocantins $\mathrm{n}^{0}$ 2.113. Disponível em:<http://dtri.sefaz.to.gov.br/>. Acesso em: 14/04/2017.

. Lei oㅜ 1.695, de 13 de junho de 2006. Dispõe sobre a concessão de incentivo fiscal aos complexos agroindustriais nas operações que especifica e adota outras providências. Diário Oficial do Estado do Tocantins ํㅜ 2.186. Disponível em: <http://dtri.sefaz.to.gov.br/>. Acesso em: 14/04/2017.

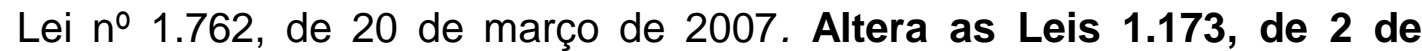
agosto de 2000, 1.201, de 29 de dezembro de 2000, 1.355, de 19 de dezembro de 2002, 1.385, de 9 de julho de 2003, 1.641, de 28 de dezembro de 2005, e 1.695, de 13 de junho de 2006. Diário Oficial do Estado do Tocantins no 1.509 . Disponível em: <http://dtri.sefaz.to.gov.br/>. Acesso em: 14/04/2017.

TRAMONTIN, Odair. Incentivos públicos a empresas privadas e guerra fiscal. Curitiba: Jurua, 2008.

VERGARA, Sylvia Constant. Projetos e relatórios de pesquisa em administração. 5ª edição. São Paulo: Atlas, 2004.

Recebido em: 27/10/2016.

Aprovado em: 19/04/2017. 